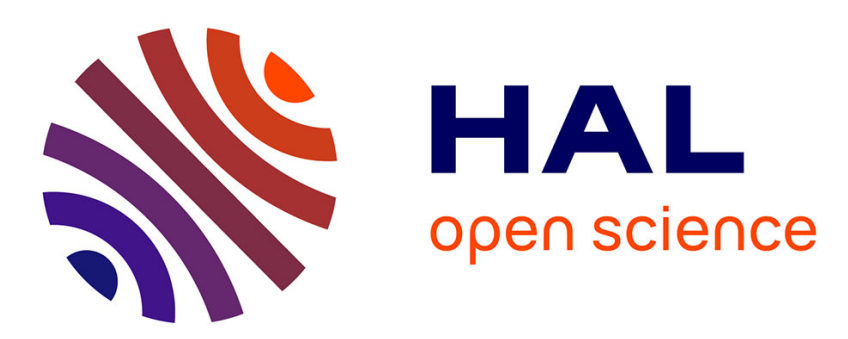

\title{
Phase evolution during the melting and recrystallization of ceramic core in the $(\mathrm{Bi}, \mathrm{Pb})-2223$ tape
}

\author{
J. Y. Li, Jean-Louis Soubeyroux, H.L. Zheng, C.S. Li, Y.F. Lu, Laureline \\ Porcar, Robert Tournier, Lian Zhou
}

\section{- To cite this version:}

J. Y. Li, Jean-Louis Soubeyroux, H.L. Zheng, C.S. Li, Y.F. Lu, et al.. Phase evolution during the melting and recrystallization of ceramic core in the (Bi,Pb)-2223 tape. Physica C: Superconductivity and its Applications, 2006, 450, pp.56-60. 10.1016/j.physc.2006.08.010 . hal-00265002

\section{HAL Id: hal-00265002 \\ https://hal.science/hal-00265002}

Submitted on 19 Mar 2008

HAL is a multi-disciplinary open access archive for the deposit and dissemination of scientific research documents, whether they are published or not. The documents may come from teaching and research institutions in France or abroad, or from public or private research centers.
L'archive ouverte pluridisciplinaire HAL, est destinée au dépôt et à la diffusion de documents scientifiques de niveau recherche, publiés ou non, émanant des établissements d'enseignement et de recherche français ou étrangers, des laboratoires publics ou privés. 


\title{
Phase evolution study on the melting and recrystallization of ceramic core in the (Bi,Pb)-2223 tape
}

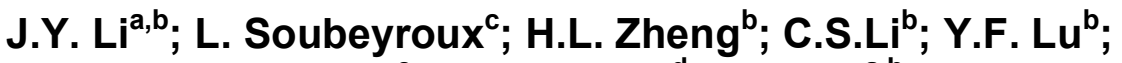 \\ L. Porcar ${ }^{c}$; R. Tournier ${ }^{\text {d }}$ L. Zhou ${ }^{a, b}$ \\ ${ }^{a}$ Northwestern Polytechnical University, Xi'an, Shaanxi 710072, PR China \\ ${ }^{b}$ Northwest Institute for Nonferrous Metal Research, 96 Wei yang Road, P.O. Box 51, Xian, Shaanxi \\ 710016, PR China \\ ${ }^{c}$ Laboratoire de Cristallographie, CRETA/CNRS, 25 avenue des Martyrs, 38042 Grenoble, France \\ ${ }^{d}$ Consortium de Recherches pour L'Emergence de Technologies Avances, CNRS, 25 avenue des \\ Martyrs, 38042 Grenoble, France
}

\begin{abstract}
The phase evolution during melting and recrystallization of ceramic core in Ag-sheathed (Bi,Pb)-2223 monofilamentary tape has been studied. The tape was fabricated by PIT process with powders containing nearly pure $(\mathrm{Bi}, \mathrm{Pb})-2223$ phase. Short samples were melted at $805^{\circ} \mathrm{C}, 808^{\circ} \mathrm{C}, 812^{\circ} \mathrm{C}, 816^{\circ} \mathrm{C}$ and $831^{\circ} \mathrm{C}$, slowly cooled down at $1.5^{\circ} \mathrm{C} / \mathrm{hr}$. and quenched in air at room temperature. X-ray diffraction (XRD) and scanning electron microscopy coupled with energy dispersive spectroscopy (SEM/EDS) were applied for the phase identification. XRD patterns of samples show that $(\mathrm{Bi}, \mathrm{Pb})-2223$ core is partially melted at $805^{\circ} \mathrm{C}, 808^{\circ} \mathrm{C}, 812^{\circ} \mathrm{C}$, and well reformed directly from the melt during the slow cooling. More $(\mathrm{Bi}, \mathrm{Pb})-2223$ phase is decomposed at temperatures higher than $816^{\circ} \mathrm{C}$ and can not recrystallize, indicating that a partial melting at some temperatures around a given temperature range is essential for $(\mathrm{Bi}, \mathrm{Pb})-2223$ phase reformation. The results of EDS analysis show that the melt composition moves from that between "2223" and "2212" stoichiometries towards 2212-like stoichiometry with increasing temperature, and $\mathrm{Bi}$-containing $2: 1$ phase is the main secondary phase. This seems to lead to the conclusion that $(\mathrm{Bi}, \mathrm{Pb})-2223$ phase decomposes incongruently into a 2212-like liquid and ( $\mathrm{Ca}, \mathrm{Sr})$-cuprates. 2:1 phase plays the most important role in (Bi, $\mathrm{Pb})-2223$ meltrecrystallization process. Our results also reveal that plate-like shape $(\mathrm{Bi}, \mathrm{Pb})-2223$ grains can be obtained via melting and recrystallization if the optimum processing conditions are used.
\end{abstract}

Keywords: (Bi,Pb)-2223 tape, melting and recrystallization, phase evolution

\section{Introduction}

For more than one decade, it was shown a slow increase in $\mathrm{J}_{c}$ of $\mathrm{Bi}-2223$ conductors in spite of the remarkable progresses achieved. The $\mathrm{J}_{\mathrm{c}}$-limiting mechanism is attributed to the weak connectivity between the grains in polycrystalline $(\mathrm{Bi}, \mathrm{Pb})-2223$ tapes ${ }^{[1]}$. The platelet alignment far from perfect, the low density of ceramic core, the presence of non-conducting and low- $T_{c}$ secondary phases, voids and cracks resulting from the deformation are responsible for the poor intergrain links ${ }^{[2]}$. A melt- processing route, via partial melting of the superconducting core, may facilitate contacts and interactions between the crystals, reduce porosities, heal cracks and increase the core density ${ }^{[3]}$. As a result, homogeneous microstructure, good grain connectivity and high critical current density in superconducting tapes can be attained. Besides, the alignment of the grains can be improved by melting processes, also combined with the applications of magnetic and/or temperature fields.

The $\mathrm{Bi}-2223$ melt-processing has long been attempted. However, following the traditional formation mechanisms of $(\mathrm{Bi}, \mathrm{Pb})-2223$ phase, this high- $\mathrm{T}_{c}$ phase occurs via nucleation from a local transient liquid, which is not stable and homogeneous, and usually far from equilibrium ${ }^{[\mathbf{4}, \mathbf{5}]}$. consequenctly, the $\mathrm{J}_{\mathrm{c}}$-limiting factors of $(\mathrm{Bi}, \mathrm{Pb})-2223$ 
conductors work still. It is believed that $(\mathrm{Bi}, \mathrm{Pb})-2223$ phase formation from a liquid being either stable or close to equilibrium will be beneficial to tape processing. Many efforts and detailed investigations have been performed on the melting behavior or melt evolution of BPSCCO system. Some works have indicated the feasibility of the Bi-2223 recrystallization from the melt. Giannini et al. ${ }^{[4,5]}$ have observed the $\mathrm{Bi}-2223$ reformation directly from the melt. The $(\mathrm{Bi}, \mathrm{Pb})-2223$ phase was found to decompose incongruently into $(\mathrm{Ca}, \mathrm{Sr})_{2} \mathrm{CuO}_{3}(2: 1),(\mathrm{Sr}, \mathrm{Ca})_{14} \mathrm{Cu}_{24} \mathrm{O}_{41}(14: 24)$ and $\mathrm{a}(\mathrm{Bi}, \mathrm{Pb})$-rich liquid phase, then recrystallized through the inverse reaction, showing that equilibrium formation of $(\mathrm{Bi}$, $\mathrm{Pb})-2223$ can be implemented.

The aim of the present work is to understand the phase evolution in the melting process of $(\mathrm{Bi}, \mathrm{Pb})-2223$ tape, as well as to investigate the feasibility of $\mathrm{Bi}-2223$ recrystallization from the melt and the effect of melting temperature on the phase relationship in 2223 system. The $(\mathrm{Bi}, \mathrm{Pb})-2223$ tape was fabricated following the standard PIT route, with near fully pre-reacted $(\mathrm{Bi}, \mathrm{Pb})-2223$ powder in pure silver tube.

A series of maximum temperatures were applied in the melting processes. Short samples were melted, slowly cooled and quenched at different temperatures. Our results indicate that $(\mathrm{Bi}, \mathrm{Pb})-2223$ phase in the silver sheath might well reform during the slow cooling. A partial melting at a defined temperature and under partial oxygen pressure is essential to $(\mathrm{Bi}, \mathrm{Pb})-2223$ phase reformation. The 2:1 phase plays an important role in the melt-recrystallization process.

\section{Experimental}

Nearly pure $(\mathrm{Bi}, \mathrm{Pb})-2223$ powder was synthesized from precursors prepared from mixtures of co-precipitated oxalates with a nominal stoichiometry $\mathrm{Bi}_{1.76} \mathrm{~Pb}_{0.34} \mathrm{Sr}_{1.83} \mathrm{Ca}_{1.91}$ $\mathrm{Cu}_{3.16} \mathrm{O}_{10+\delta}$ after about 150 hours annealing at $840-857^{\circ} \mathrm{C}$ in air with intermediate grindings. Silver-sheathed $(\mathrm{Bi}, \mathrm{Pb})-2223$ tapes were prepared by standard PIT method. Pre-reacted powder, which contains $>94 \%(\mathrm{Bi}, \mathrm{Pb})-2223$ phase and traces of $\mathrm{Bi}-2201$ and $(\mathrm{Ca}, \mathrm{Sr})$-cuprates, was packed into silver tube and the composite was drawn and rolled into mono-filamentary tapes with a width of 3-4 mm and thickness of $0.2-0.3 \mathrm{~mm}$.

Short samples, with length of $60 \mathrm{~mm}$ cut from $(\mathrm{Bi}, \mathrm{Pb})-2223$ tape and sealed at both ends, were subjected to the melting treatment in a tubular furnace under flowing $7.5 \% \mathrm{O}_{2}$ balanced with argon. The gas-flow rate was $15 \mathrm{ml} / \mathrm{min}$. Samples were initially ramped up at $5{ }^{\circ} \mathrm{C} / \mathrm{hr}$. to a temperature $5^{\circ} \mathrm{C}$ lower than maximum heating temperature $\left(T_{p}\right)$ then at $0.2{ }^{\circ} \mathrm{C} / \mathrm{hr}$. to $T_{p^{\prime}}$ dwelled there for $30 \mathrm{~min}$, subsequently slow-cooled at 1.5 ${ }^{\circ} \mathrm{C} / \mathrm{hr}$. from $T_{p}$ to the final temperature $\left(T_{E}\right)$ of treatment, and quenched in air at room temperature as shown in Figure $1.805^{\circ} \mathrm{C}, 808^{\circ} \mathrm{C}, 812^{\circ} \mathrm{C}, 816^{\circ} \mathrm{C}, 831^{\circ} \mathrm{C}$ as $\mathrm{T}_{\mathrm{p}} \mathrm{s}$ were used in order to obtain the appropriate temperatures at which $(\mathrm{Bi}, \mathrm{Pb})-2223$ phase could reform from the melt. Phase identification was performed by means of X-ray diffraction analysis (XRD). Scanning electron microscopy coupled with energy dispersive spectroscopy (SEM/EDS) was applied to characterize the cross-section and the surfaces near to silver sheath of quenched ceramics cores.

\section{Results and discussion}

\subsection{Melting behavior}

It is believed that the maximum temperature plays a central role for meltprocessing of the Bi-based superconducting phase ${ }^{[6]}$. Control of this parameter is essential for avoiding too much segregation from the melt forming large ( $\mathrm{Ca}, \mathrm{Sr}$ )-cuprates and $\mathrm{CuO}$ precipitates and also bismuth and oxygen volatilization. Figure 2 shows the $\mathrm{X}$ ray diffraction patterns for the samples quenched after the melting of $(\mathrm{Bi}, \mathrm{Pb})-2223$ tapes at different $\mathrm{T}_{\mathrm{p}} \mathrm{s}$. The $(\mathrm{Bi}, \mathrm{Pb})-2223$ diffraction peaks, which are predominantfor the tape not suffered melting treatment, become subordinate gradually up to disappear along with the $\mathrm{T}_{\mathrm{p}}$ increase from $805^{\circ} \mathrm{C}$ to $831^{\circ} \mathrm{C}$. Bi-2201 peaks, accordingly, turn into the leading 
ones. 2:1 AEC fractions clearly increased in comparison to the tape before melting. Some other $(\mathrm{Ca}, \mathrm{Sr})$-cuprates with different $\mathrm{Sr}$ : Ca ratios were also found, indicating that these phases precipitated from the $(\mathrm{Bi}, \mathrm{Pb})-2223$ decomposition. Besides, $\mathrm{CaO}$ peaks arise in the samples heated above $808^{\circ} \mathrm{C}$ and reach the strongest at $T_{p}$ Figure 2: X-ray diffraction.... $=816^{\circ} \mathrm{C}$, meanwhile, the traces of $\mathrm{CuO}$ become clear. $\mathrm{CaO}$ and $\mathrm{CuO}$ precipitates formed by melting $(\mathrm{Bi}, \mathrm{Pb})-2223$ core are the decomposition products of $(\mathrm{Ca}, \mathrm{Sr})$-cuprates ${ }^{[\mathrm{7}]}$. No $(\mathrm{Bi}, \mathrm{Pb})$-rich crystalline phases grow when the $(\mathrm{Bi}, \mathrm{Pb})-2223$ decomposed, meaning that $(\mathrm{Bi}, \mathrm{Pb})-2223$ phase may incongruently melt into a $(\mathrm{Bi}, \mathrm{Pb})-$ rich liquid and $(\mathrm{Ca}, \mathrm{Sr})$-cuprates. This is in agreement with the studies in ref. $[4,5]$.

From Figure 2, it is surprising to find that the $(\mathrm{Bi}, \mathrm{Pb})-2223$ core begins to decompose into $\mathrm{Bi}-2201$ phase and $(\mathrm{Ca}, \mathrm{Sr})$-cuprates even at the temperatures lower than $805^{\circ} \mathrm{C}$ and melt fully at ones lower than $831^{\circ} \mathrm{C}$ under the present experimental conditions, very different from that reported by other researchers. This could be attributed to the combined effects of the low oxygen partial pressure, the presence of silver as sheath and the composition of the precursor. This result should have a beneficial influence on the $\mathrm{Bi}-2223$ system, preventing more $\mathrm{Ca}$ and $\mathrm{Cu}$ segregation and bismuth and oxygen volatilization from the melt.

Some SEM images are shown in Figure 3. The influence of the maximum heating temperature can be clearly observed. Larger dimensions and quantities of blacker secondary-phases appear in the matrix of samples melted at high maximum temperatures, indicating more 2223 decomposed as $\mathrm{T}_{\mathrm{p}}$ rises up. The main secondary phases found by SEM/EDS are Bi-containing $2: 1$ with the composition $\mathrm{Bi}_{2.05-2.52} \mathrm{Sr}_{3.91 \text { - }}$ ${ }_{5.93} \mathrm{Ca}_{18.30-19.81} \mathrm{Cu}_{10.36-13.33} \mathrm{O}_{\mathrm{x}}$. Some small precipitates were identified as Cu-rich phases with the composition $\mathrm{Bi}_{8.38-14.19} \mathrm{~Pb}_{0.62-1.24} \mathrm{Sr}_{7.96-13.06} \mathrm{Ca}_{7.11-16.78} \mathrm{Cu}_{21.31-51.45} \mathrm{O}_{\mathrm{x}}$. According to the XRD patterns above, the matrix of ceramic core after melting and subsequent quenching could consist of a mixture of an amorphous phase with 2223 phase not completely melted and crystallized 2201 plates or just the latters. Interestingly, the SEM/EDS analysis carried out in the present work shows that the $2: 1$ islands are not embbeded in a Bi-2201 matrix after any treatments. The matrix compositions for the quenched melted samples at different temperatures are shown in the Table 1. It shows that the matrix compositions are located between the 2223 and 2212 stoichiometries, and $\mathrm{Ca}$ content in the matrix decreases gradually as more 2223 decomposes into (Ca,Sr)-cuprates at higher temperature, indicating that the melt composition moves from 2223 towards 2212 as temperature increases. These results, together with the discussion above, seem to allow the conclusion that 2223 may decompose into 2212-like liquid and (Ca,Sr)-cuprates, mainly 2:1 phase. That the XRD patterns of quenched samples exhibited high Bi-2201 content could not be clarified in our present work. It was considered as the cause of its high crystallization rate from melt, even during quenching ${ }^{[8]}$. Perhaps the dimensions of this precipitate emerging via quenching in our specimens are too fine to be detected by EDS.

Table 1

The matrix compositions after melting at different $T_{\mathrm{p}}$

\begin{tabular}{lcccc}
\hline$T_{\mathrm{p}}$ & $805^{\circ} \mathrm{C}$ & $808^{\circ} \mathrm{C}$ & $812^{\circ} \mathrm{C}$ & $816^{\circ} \mathrm{C}$ \\
\hline $\mathrm{Bi}$ & $9.09-12.44$ & $9.60-10.95$ & $10.77-12.94$ & $9.87-10.27$ \\
$\mathrm{~Pb}$ & $0.65-1.18$ & $0.97-1.16$ & $0.96-1.53$ & $0.0-0.68$ \\
$\mathrm{Sr}$ & $8.96-11.24$ & $9.90-10.37$ & $10.89-11.13$ & $9.96-10.18$ \\
$\mathrm{Ca}$ & $7.33-8.08$ & $6.21-7.15$ & $5.33-5.58$ & $5.16-5.19$ \\
$\mathrm{Cu}$ & $10.64-14.29$ & $10.69-13.16$ & $9.29-10.48$ & $10.02-10.88$ \\
\hline
\end{tabular}


Figure 4 shows the XRD patterns of $(\mathrm{Bi}, \mathrm{Pb})-2223$ tape after melting at $812^{\circ} \mathrm{C}$, cooled down to $788^{\circ} \mathrm{C}$ at $1.5^{\circ} \mathrm{C} / \mathrm{hr}$ and quenched in air. The $(\mathrm{Bi}, \mathrm{Pb})-2223$ peaks have reverted to their predominant status, and that $\mathrm{Bi}-2201$ peaks have almost disappeared, and the amount of $2: 1$ phase has been reduced obviously, indicating that the $(\mathrm{Bi}, \mathrm{Pb})$ 2223 phase is well-reformed directly from the melt. Similarly, clear indications of 2223 reformation were found in another set of experiment, in which silver-sheathed tapes were heated to $808{ }^{\circ} \mathrm{C}$ and slowly cooled down to $784^{\circ} \mathrm{C}$ at the same rate. However, no 2223 was reformed from the melt above $816^{\circ} \mathrm{C}$. It indicates that this temperature is too high for melt-processing. Actually, an excessively too high temperature produces many large 2:1 precipitates in the melting specimens (see Figure3 (d)). The development of large $2: 1$ islands will prevent the 2223 formation in those samples, due to degradation of stoichiometry of the remaining ceramic phase, as well as increasing the difficulty in dissolving such large precipitates to provide sufficient $\mathrm{Sr}$ and $\mathrm{Ca}$ to a $(\mathrm{Bi}, \mathrm{Pb})$-rich melt, in the amount necessary to form 2223.

It is obvious that a partial melting at some temperatures in an appropriate temperature range is important for $(\mathrm{Bi}, \mathrm{Pb})-2223$ phase reformation.

The SEM images of the samples resulting from the treatment at $T_{p}=812^{\circ} \mathrm{C}$ and slowly cooled down to $788^{\circ} \mathrm{C}$ are shown in Figure 5. The EDS results are consistent with the previous XRD observations. ( $\mathrm{Bi}, \mathrm{Pb})-2223$ phase with the composition of $\mathrm{Bi}_{9.49} \mathrm{~Pb}_{0.93-}$ ${ }_{1.04} \mathrm{Sr}_{9.79-9.86} \mathrm{Ca}_{7.88-8.18} \mathrm{Cu}_{14.19-14.98} \mathrm{O}_{\mathrm{x}}$ reformed directly from the melt becomes the dominant phase. The main residual secondary-phase islands have been identified as the 2:1 phase with the composition of $\mathrm{Bi}_{0-0.80} \mathrm{Sr}_{3.42-4.29} \mathrm{Ca}_{22.04-23.35} \mathrm{Cu}_{13.65-13.57}$

Most of these particles had been consumed in the samples slowly cooled to $788^{\circ} \mathrm{C}$ from $812^{\circ} \mathrm{C}$, but some large grains remained in the samples slow-cooled down to the same temperature (see Figure 3 (a), (b)).

The cross-section image of the sample slowly cooled to $788^{\circ} \mathrm{C}$ reveals that those regions have a plate-like shape, in comparison to the ones of the specimen melted at $812^{\circ} \mathrm{C}$ (see Figure 3 (c) and (d)). The EDS analysis of such plates gives $\mathrm{Bi}_{6.77-7.86} \mathrm{~Pb}_{0 \text { - }}$ ${ }_{0.83} \mathrm{Sr}_{7.96-8.42} \mathrm{Ca}_{6.45-8.26} \mathrm{Cu}_{10.50-14.34} \mathrm{O}_{x}$ compositions, falling in the vicinity of the 2223 primary phase field, indicating the presence of $(\mathrm{Bi}, \mathrm{Pb})-2223$ phase. Their morphological evolution suggests that partial melting and recrystallization has taken place.

The fact that 14:24 AEC, which was found as an equilibrium product of the 2223 decomposition and reformation ${ }^{[4,5]}$, has not been detected in our samples, and is probably associated to its limited stability range, as well as to the present experimental conditions and precursor composition. The exact nature of the liquid in equilibrium with the 2223 phase remains to be clarified. Our results suggest that $2: 1$ phase is the most important secondary phase involved in the melting recrystallization, in relations to 2223 tapes, and plate-like 2223 grains may be obtained if the optimal treatment conditions can be found.

\section{Summary}

The phase evolution during melting and recrystallization of ceramic core in Agsheathed $(\mathrm{Bi}, \mathrm{Pb})-2223$ monofilamentary tape was studied. The tape was fabricared by PIT process with powders containing nearly pure $(\mathrm{Bi}, \mathrm{Pb})-2223$ phase. Short samples were melted at different temperatures, slowly cooled at $1.5^{\circ} \mathrm{C} / \mathrm{hr}$. and quenched in air at room temperature. XRD and SEM/EDS were applied to the phase identification. XRD patterns of the samples being melted and quenched reveal that the ceramic core was partially melted at temperatures lower than $805^{\circ} \mathrm{C}$ and fully melted at ones above $831^{\circ} \mathrm{C}$, $\mathrm{Bi}-2201$ becomes gradually the predominant phase along with temperature increasing, $2: 1$ is the main secondary phase. The results of EDS analysis show that the melt composition moves from that between "2223" and "2212" stoichiometries towards 2212like with temperature increasing, indicating that (Bi, $\mathrm{Pb})-2223$ core decomposes incongruently into a 2212-like liquid and ( $\mathrm{Ca}, \mathrm{Sr})$-cuprates, mainly Bi-containing 2:1 phase. During the slow cooling, $(\mathrm{B}, \mathrm{Pb})-2223$ phase well reforms directly from the melt. 
Too high temperature is not helpful to $(\mathrm{Bi}, \mathrm{Pb})-2223$ reformation. It is indicated that a partial melting at some temperatures in an appropriate temperature range is essential to $(\mathrm{Bi}, \mathrm{Pb})-2223$ phase reformation. 2:1 phase plays most important role in $(\mathrm{Bi}, \mathrm{Pb})-2223$ melt-recrystallization process. Plate-like shape $(\mathrm{Bi}, \mathrm{Pb})-2223$ grains can be attained via melting and recrystallization if the optimum processing conditions are used.

\section{Acknowledgements}

We would like to thank for financial support the PRA "Materiaux" of the Chinese Ministry of Science and Technology (MOST) of the People's Republic of China and the French Ministry of Foreign Affairs (MAE) and Ministry of Education (MENESR). The work has been done in the framework of the French-Chinese International Associated Laboratory LAS2M. J.Y. Li wishes also to acknowledge CRETA/CNRS, in Grenoble, France, where the melting experiments and XRD analysis were done.

\section{References}

[1] R Zeng, et, Supercond. Sci. Technol.11 (1998) 770-776.

[2] C. Beneduce, E. Giannini, R. Passerini, G. Witz, B. Seeber, R. Flukiger, Physica C 372376 (2002) 980-983.

[3] E Cecchetti, P J Ferreira, J B Vander Sande, Supercond. Sci. Technol.13 (2000) $1270-1278$

[4] E Giannini, I Savysyuk, V Garnier, R Passerini, P Toulemonde, R Flukiger, Supercond. Sci. Technol.15 (2002) 1577-1586.

[5] E. Giannini, R. Passerini, P. Toulemonde, E. Walker, M. Lomello-Tafin, D. Sheptyakov, R. Flukiger, Physica C 372-376(2002) 895-898.

[6] 15. Buhl, D.; Lang, T.; Cantoni, M.; Risold, D.; Hallstedt, B.; Gauckler, L.J. Physica C, v. 257, p. $151,1996$.

[7] X.Y. Lu, A. Nagata, K. Sugawara, S. Kamada, Physica C, v. 354, p. 313, 2001.

[8] A. Polasek, P. Majewski, E.T. Serra, F. Rizzo, F. Aldinger, Mat. Res. vol.7 No.3 São

Carlos July/Sept. 2004 


\section{FIGURE Caption}

Figure 1. Temperature profile of melting experiments

Fig. 2. X-ray diffraction patterns of (Bi,Pb)-2223 tapes after quenched from different maximum temperatures

Fig. 3. SEM images of ( $\mathrm{Bi}, \mathrm{Pb})-2223$ tapes after quenched from different maximum temperatures (backscattered) (a) 805 C; (b) 808 C; (c) 812 C and (d) $816 \mathrm{C}$.

Fig. 4. X-ray diffraction patterns of $(\mathrm{Bi}, \mathrm{Pb})-2223$ tape after melted at $\mathrm{Tp}=812$ $\mathrm{C}$ and cooled down at $0.025 \mathrm{C} / \mathrm{min}$.

Fig. 5. SEM images of (Bi,Pb)-2223 tapes after quenched from $812 \mathrm{C}(\mathrm{a}, \mathrm{c})$ and slow-cooled down to $788 \mathrm{C}(\mathrm{b}, \mathrm{d}),(\mathrm{a})$ and (b) surfaces of ceramic core near the Ag-sheath (backscattered), (c) and (d) cross-sections

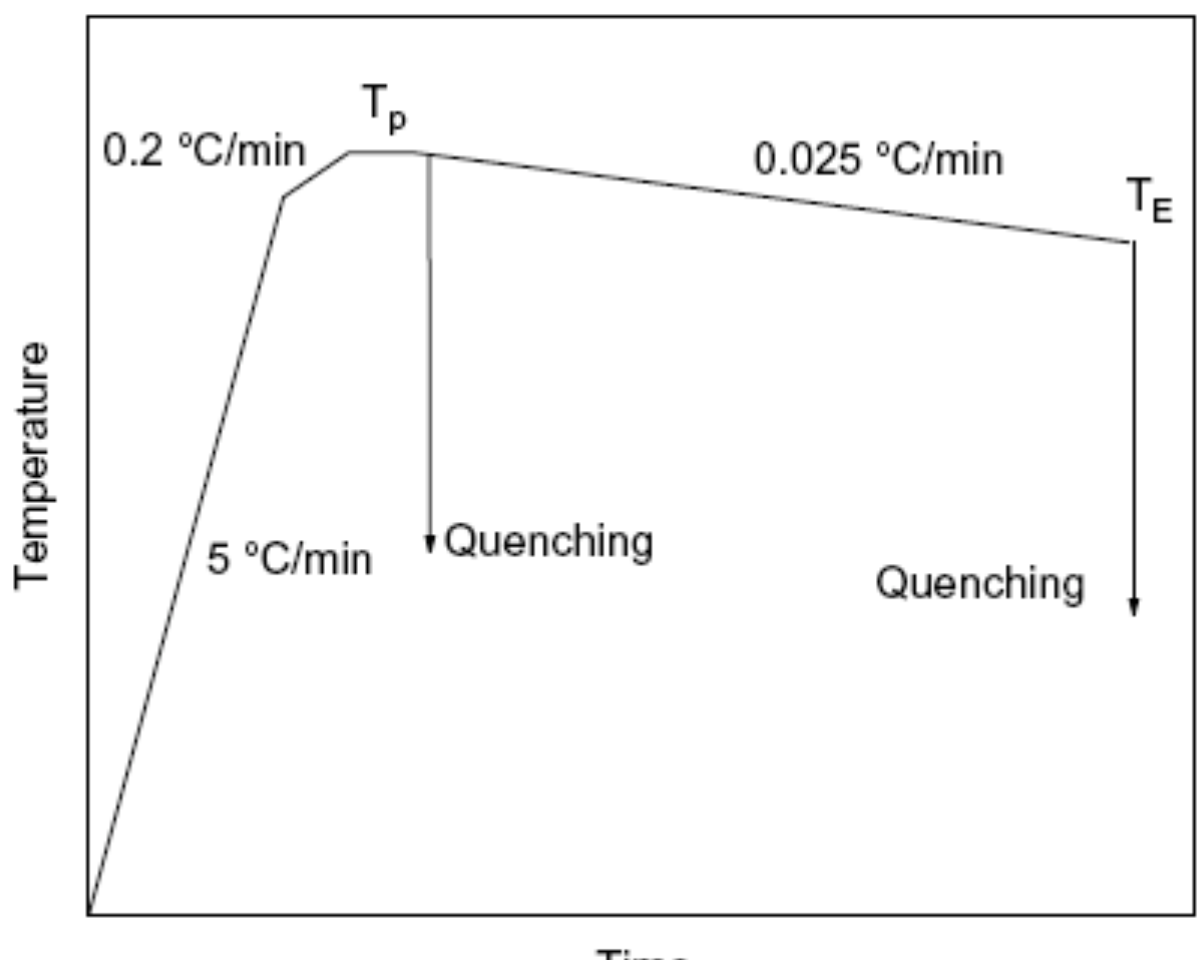

Time

Fig.1 


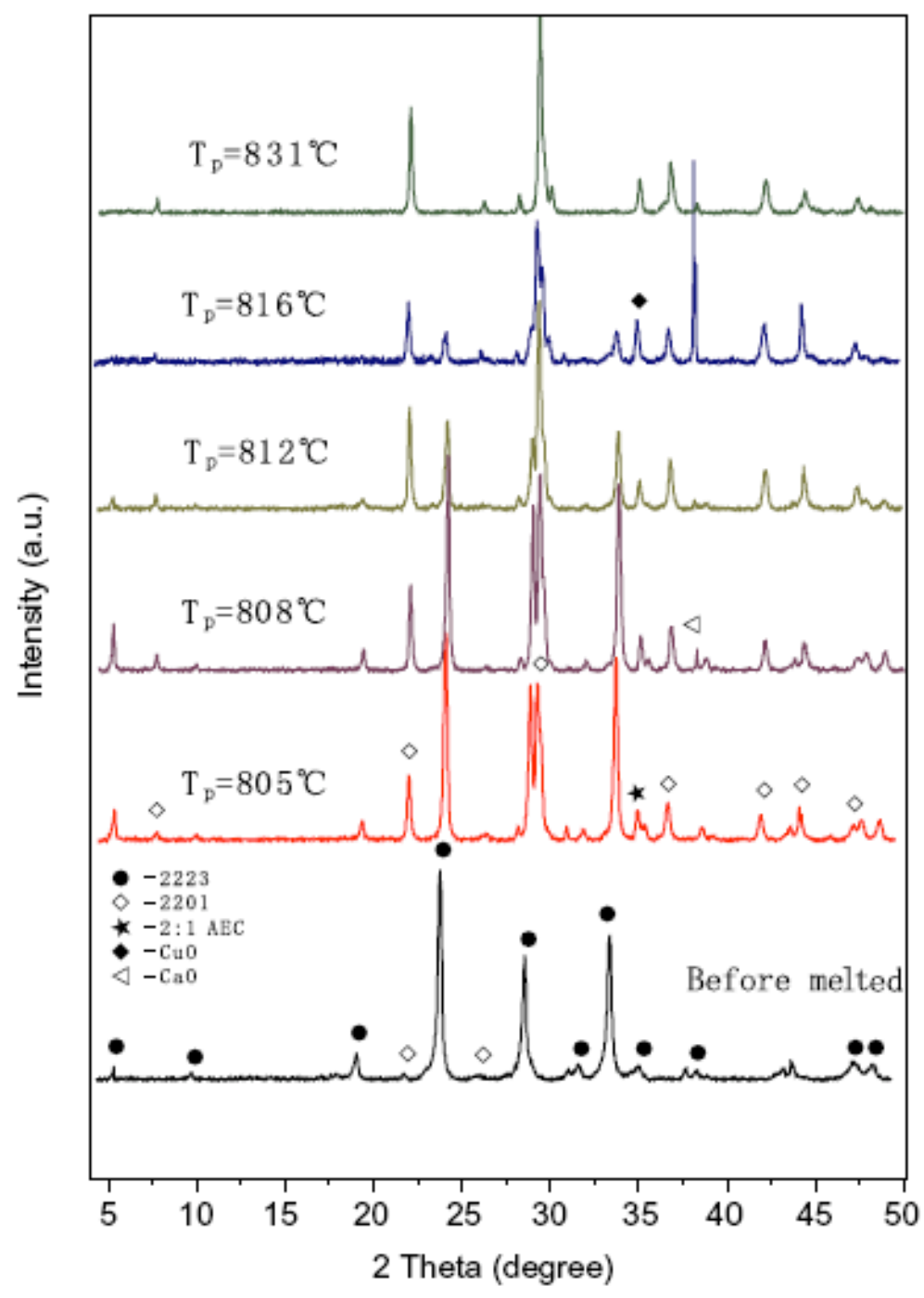

Fig. 2 

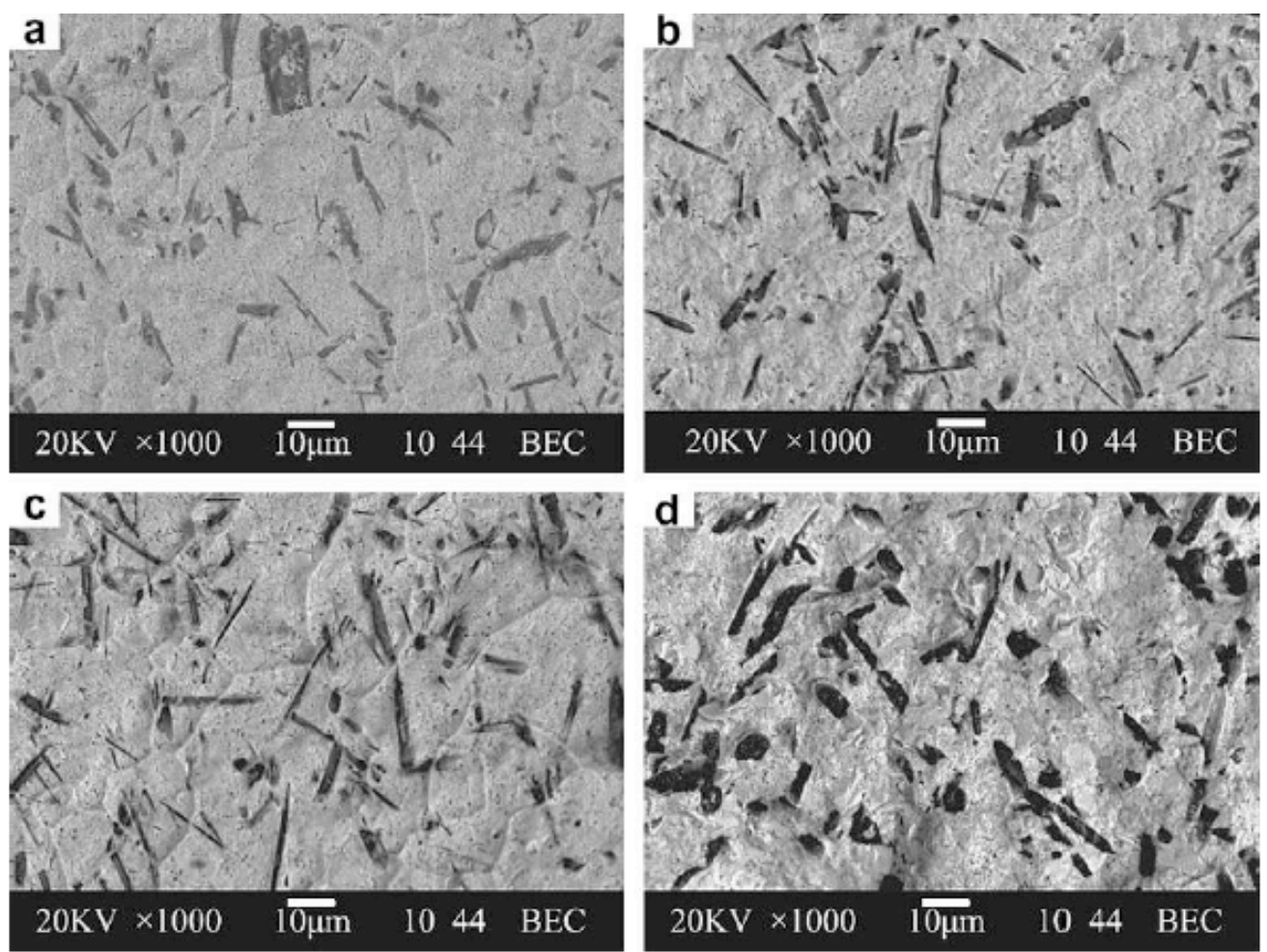

Fig. 3

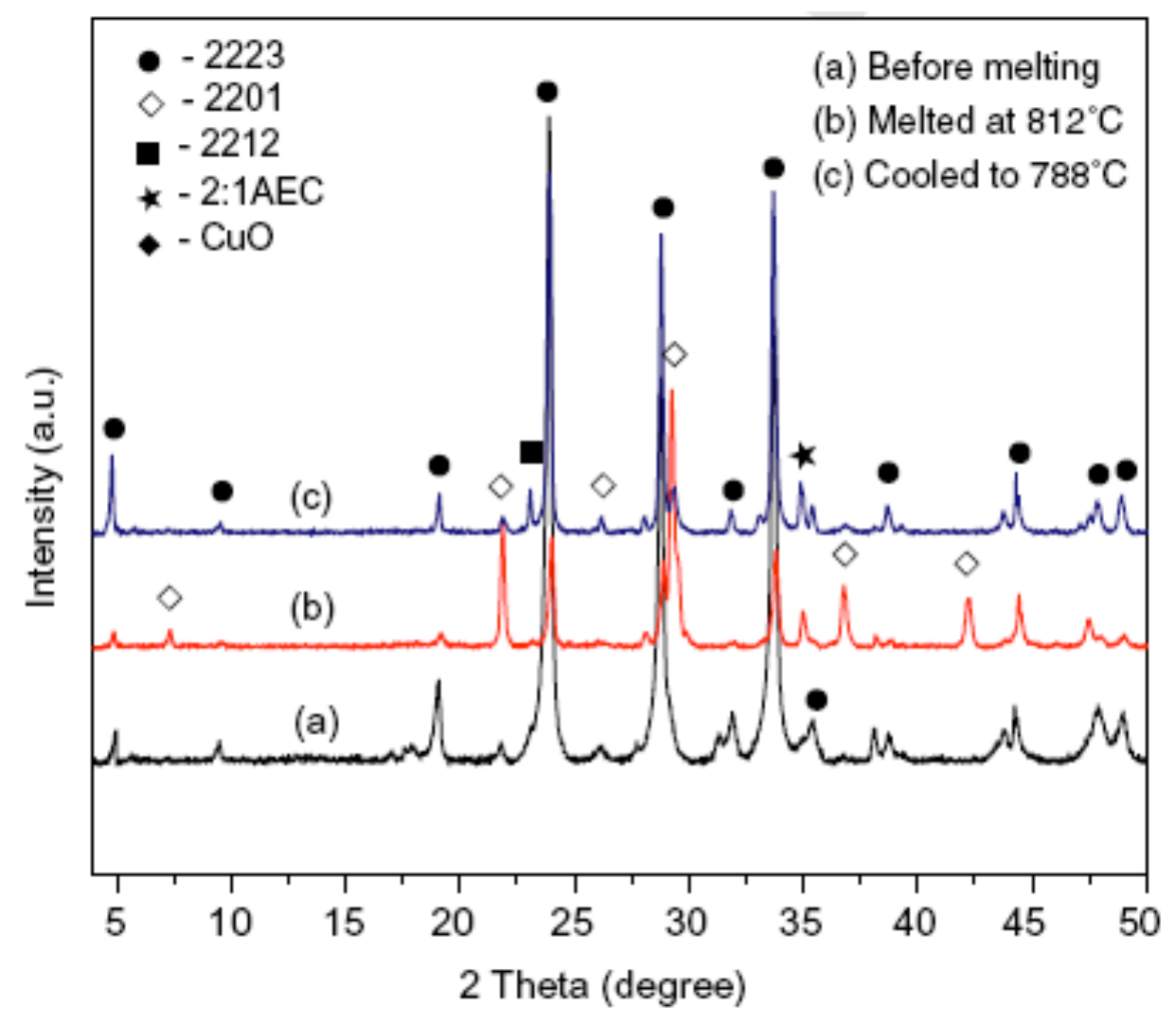

Fig.4 

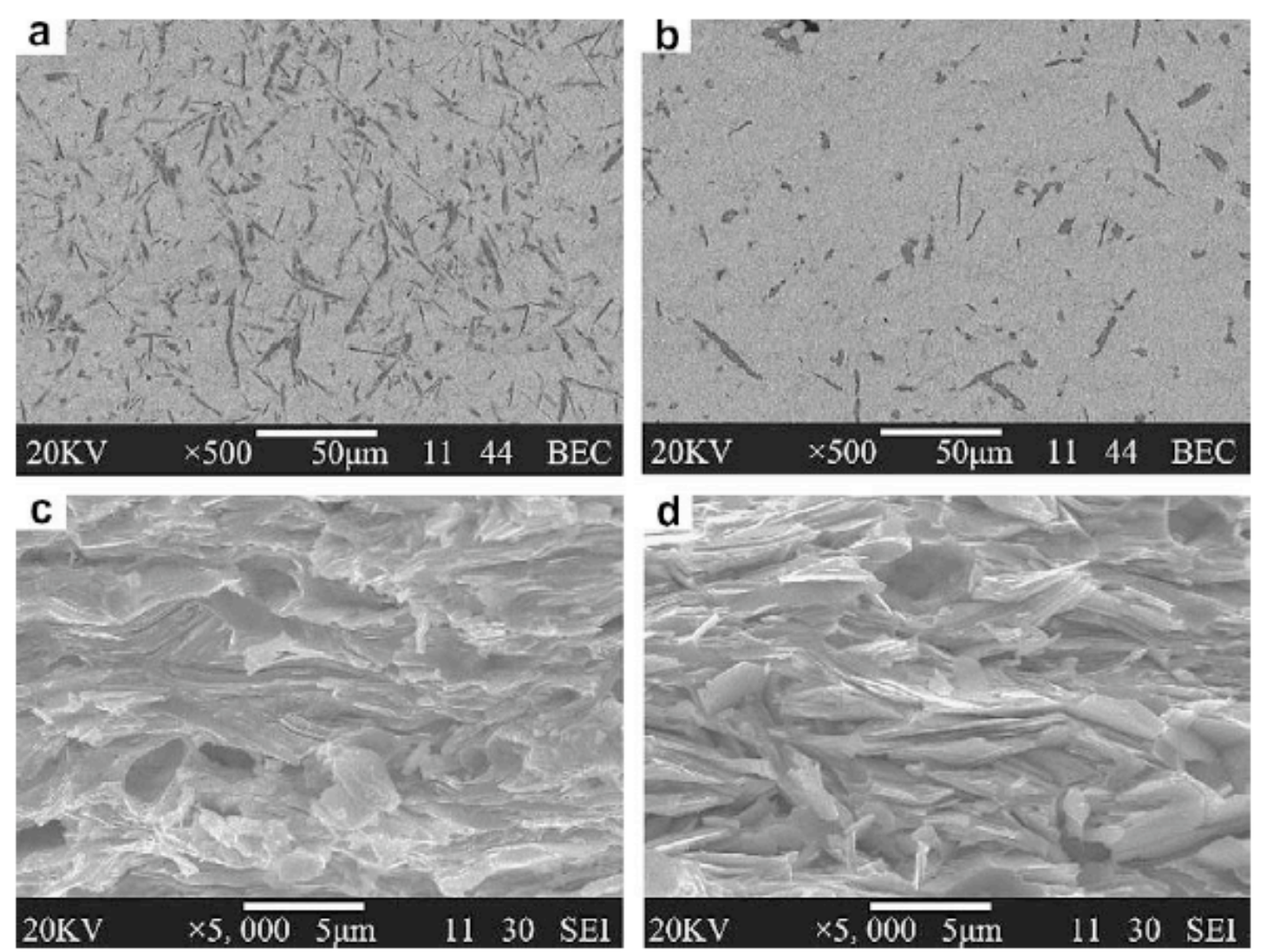

Fig. 5 